\title{
Antioxidant Effect of Egg Yolk Peptides against Tert-butyl Hydroperoxide Induced Oxidative Stress in Caco-2 Colon Cancer Cells
}

\author{
Marwa Yousr ${ }^{1, *}$, Akram Aloqbi ${ }^{2}$, Ulfat Omar ${ }^{3}$, Nazlin K Howell ${ }^{1}$ \\ ${ }^{1}$ Faculty of Health and Medical Sciences, School of Biosciences and Medicine, University of Surrey, UK \\ ${ }^{2}$ Biology Department, Faculty of Science and Arts-Alkamel, University of Jeddah, Saudi Arabia \\ ${ }^{3}$ Biochemistry Department, Faculty of Science, King Abdulaziz University, Saudi Arabia
}

Copyright $(\mathrm{C} 2016$ by authors, all rights reserved. Authors agree that this article remains permanently open access under the terms of the Creative Commons Attribution License 4.0 International License.

\begin{abstract}
Oxidative stress can damage lipids, proteins and DNA. The effect of hydrolysed, purified defatted egg yolk protein by-product (fraction EYGF-23) on oxidative stress in Caco-2 colon cancer epithelial cells was investigated for the first time. Caco-2 cells exposed to toxic $3 \mathrm{mM}$ tert-butyl hydroperoxide (t-BHP) for 2 hours were protected when pretreated with $1.0 \mathrm{mg} / \mathrm{ml}$ EYGF- 23 for 24 hours. The peptides inhibited intracellular reactive oxygen species (ROS) $(60.0 \%)$ and malondialdehyde (MDA) $(24.2$ $\mu \mathrm{g} / \mathrm{ml}$ ) production, compared to cells treated with only t-BHP $(75.3 \%$ and $32.2 \mu \mathrm{g} / \mathrm{ml}$ respectively). EYGF-23 inhibited caspase $3 / 7$ activity in stressed cells, thereby protecting cells from induced caspase-dependent apoptosis. Further, total glutathione level and superoxide dismutase activity were significantly elevated to $0.29 \mu \mathrm{M}$ and $55.10 \%$ respectively, in cells pretreated with EYGF-23, compared to t-BHP treatment alone $(0.10 \mu \mathrm{M}$ and $44.22 \%$ respectively). Peptides WYGPD, TMFPSA and WIHNENQGF and hydrophobic amino acids tyrosine $(\mathrm{Y})$ and tryptophan $(\mathrm{W})$ contributed to cellular antioxidant activity against oxidative stress in colon epithelial cells and may have nutraceutical applications.
\end{abstract}

Keywords Egg Yolk By-product, Bioactive Peptides, Oxidative Stress, Glutathione, Superoxide Dismutase, Reactive Oxygen Species

\section{Introduction}

Reactive oxygen species (ROS) are produced in living cells as a result of normal cell metabolism and xenobiotic detoxification. Oxidative stress is a consequence of an excess of ROS, which participate in cellular damage by reacting with lipid membranes, proteins, and DNA. The effects of oxidative stress in mammalian cells range from rapid cell mortality to disturbance of many cell signaling processes [1]. As a result, ROS are implicated in the pathogenesis of many diseases that include cardiovascular diseases [2] and certain cancers [3]. Cellular antioxidative enzymes such as superoxide dismutase (SOD), glutathione peroxidase (GPx) and catalase (CAT) can protect cell membranes and cellular content by scavenging ROS. Under certain conditions, excess ROS formation overwhelms the prooxidant/antioxidant balance despite the presence of the antioxidant defense system [4]. Therefore, there is growing interest to find food-derived antioxidants that can protect tissues from free radical-mediated oxidative stress. Some dietary protein and plant polyphenol have been suggested to have antioxidant effect by upregulating intracellular defense systems or intercepting ROS formation [5]. The human colon carcinoma (Caco-2) cell line was applied in this research because it displays morphological and physiological characteristics that are similar to intestinal epithelial cells when differentiated [6]. The purpose of using $t$-BHP was to generate oxidative stress that results in cell injury that initiates intestinal degenerative processes [7]. Once $t$-BHP penetrates the cell membrane, it can easily degrade to alkoxyl and peroxyl radicals to generate ROS. The resulting impact of ROS generated by $t$-BHP leads to a depletion of glutathione (GSH), peroxidation of membrane lipids, DNA damage and a loss of mitochondrial membrane potential [8]. Previous studies indicated that a phosvitin oligophosphopeptide, isolated from egg yolk protein, protected intestinal cells from oxidative stress induced by hydrogen peroxide by suppressing lipid oxidation, enhancing the synthesis of GSH and increasing its level [9]. Prevention of the deleterious effects of excess ROS is beneficial to protect cellular membranes and their components. Therefore, the aim of this novel study was to use cultured Caco-2 cells as an epithelial model to investigate the antioxidant effect of isolated egg yolk peptides in cells exposed to pro-oxidant $t$-BHP. 


\section{Materials and Methods}

\subsection{Isolation and Purification of Peptide}

Egg yolk gel filtration fraction-23 (EYGF-23) was isolated and purified as described by Yousr and Howell [10]. Briefly proteins from defatted egg yolk were isolated and hydrolysed with pepsin $(1: 35 \mathrm{w} / \mathrm{w})$ and pancreatin $(1: 25$ $\mathrm{w} / \mathrm{w})$. The hydrolysate was fractionated using ultrafiltration cartridges with 2, 5 and $10 \mathrm{MW}$ cut-off membranes. The 2 $\mathrm{kDa}$ fraction was separated by gel filtration using Sephadex G-25 and $50 \mathrm{mM}$ sodium phosphate buffer. The fraction (EYGF-23) with the highest antioxidant activity in non-cellular in vitro experiments was selected [10].

\subsection{Cell Culture and Treatment}

Human colon epithelial carcinoma cell line (Caco-2) was obtained from European Collection of Cell Cultures (ECACC). Passage number used for all experiment 43, 44 and 45. Caco-2 cells were grown in Dulbecco's modified Eagle's cell culture medium (DMEM) supplemented with $20 \%$ foetal bovine serum (FBS), 1\% glutamine, $1 \%$ Non-essential amino acids (NEAA), and $1 \%$ penicillin/streptomycin. Cells were cultured and incubated at $37^{\circ} \mathrm{C}$ in a $5 \% \mathrm{CO}_{2}$ humidified incubator. Cultured cells were exposed to peptide treatment when reach $50 \%$ confluence and incubated for 24 hours. In order to induce stress, $3 \mathrm{mM}$ $t$-BHP was added to cultured cells and incubated for an additional 2 hours [11].

\subsection{Cell Viability}

To determine the effect of EYGF-23 on cell proliferation and viability, the MTT (3-[4,5-dimethylthiazolyl-2]-2,5-dip henyl-tetrazolium bromide) assay was conducted [11]. Cells were cultured in 96-well tissue culture plates by adding 200 $\mu l$ of a cell suspension at a concentration of $1 \times 10^{4}$ cells/well. Cultured cells were treated with EYGF-23 and incubated for 24 hours followed by 2 hours incubation with $3 \mathrm{mM} t$-BHP. After incubation, $20 \mu \mathrm{l}$ of $5 \mathrm{mg} / \mathrm{ml}$ MTT dye was added to each well. After 4 hours, the culture medium was aspirated and $200 \mu 1$ of Dimethyl sulphoxide (DMSO) were added. Colour intensity was measured at $492 \mathrm{~nm}$ using a plate reader (Behring Co, Marburg, Germany).

\subsection{Measurement of Intracellular ROS}

The intracellular ROS level in Caco-2 cells was evaluated by flow cytometry with the use of a non-fluorescent cell permeable probe $\left(\mathrm{CM}-\mathrm{H}_{2} \mathrm{DCFDA}\right)$ [11]. Cells were seeded in $25 \mathrm{~cm}^{2}$ tissue culture flasks at a concentration of $1 \times 10^{6}$ cells $/ \mathrm{ml}$. Cultured cells were treated with EYGF-23 and incubated for 24 hours followed by 2 hours incubation with $3 \mathrm{mM} t$-BHP. After incubation, cells were washed with phosphate buffered saline (PBS) twice then harvested using trypsin. Trypsinised cells were centrifuged for 3 minutes at
$150 \mathrm{xg}$. After media aspiration, cells were re-suspended in $500 \mu \mathrm{PBS}$ and loaded with $10 \mu \mathrm{l}$ of $5 \mu \mathrm{M}$ DCFDA (prepared freshly in DMSO). Loaded cells were incubated for 30 minutes at $37^{\circ} \mathrm{C}$ in a humidified atmosphere with $5 \%$ $\mathrm{CO}_{2}$. Cells were then analyzed using a BD FACS Canto flow cytometer (BD Biosciences, California, USA). At least 10,000 events were evaluated.

\subsection{Thiobarbituric Acid Reactive Species (Tbars) Formation in Caco-2 Cells}

Malondialdehyde (MDA) formed as a secondary product of lipid oxidation was measured using TBARS assay [11]. Briefly, treated cells were lysed with $20 \%$ tricholoroacetic acid (TCA). After lysing, $2 \mathrm{ml}$ of $0.7 \%$ thiobarbituric acid (TBA) was added and the cell solution was heated at $100{ }^{\circ} \mathrm{C}$ for one hour. After cooling, the solution was centrifuged for 10 minutes at $150 \mathrm{xg}$ and measured at $532 \mathrm{~nm}$.

\subsection{The Caspase-Glo 3/7 Assay}

Caspase-Glo $^{\circledR}$ 3/7 Assay was obtained from Promega (Southampton, UK). This assay was used to measure the caspase activity in treated cells. The assay was conducted according to the manufacturer's instructions. Luminescence produced was measured using a luminometer $\left(\right.$ GloMax $^{\circledR} 96$ Luminometer, Promega, USA).

\subsection{Effect of Egg Yolk Peptide on Endogenous Antioxidant Defence Systems in Caco-2 Cells under Oxidative Stress}

\subsubsection{Preparation of Cell Lysate}

Culture medium from each tested flask was collected in 15 $\mathrm{ml}$ centrifuge tubes and attached cells were washed with 1 $\mathrm{ml}$ PBS. After washing, cells were harvested using $3 \mathrm{ml}$ trypsin. Trypsinised cells were re-suspended in their corresponding collected medium and centrifuged for 3 minutes at $150 \mathrm{x} g$. The supernatant was decanted and cell pellets were lysed using $300 \mu \mathrm{l}$ lysis buffer $(50 \mathrm{mM}$ Tris HCL, $150 \mathrm{mM} \mathrm{NaCl}, 1 \%$ Nonidet P40 (NP-40), 0.2\% SDS solution, $20 \mu \mathrm{M}$ PMSF, $1 \mu \mathrm{g} / \mathrm{ml}$ Aprotinin, $1 \mu \mathrm{g} / \mathrm{ml}$ Leupeptin, and $1 \mathrm{mM} \mathrm{Na}_{3} \mathrm{VO}_{4}$ ).. After lysing, cells were kept in ice for 20 minutes and stored at $-80^{\circ} \mathrm{C}$ for further use in the following experiments.

\subsubsection{Determination of Total Glutathione Concentration}

The total reduced and oxidized (GSH and GSSG respectively) glutathione concentration was measured quantitatively using the OxiSelect ${ }^{\mathrm{TM}}$ Total Glutathione (GSSG/GSH) Assay Kit (catalog number STA-312, Cell Biolabs, INC., Cambridge, UK) according to the manufacturer's instructions.

\subsubsection{Superoxide Dismutase Assay}

Superoxide dismutase (SOD) activity was measured using the SOD Activity Assay Colorimetric Kit (catalog number 
ab65354, Abcam $^{\circledR}$, Cambridge, UK) according to the manufacturer's instructions.

\subsubsection{Catalase Assay}

In order to measure the level of catalase in Caco-2 cell lysate, The OxiSelect ${ }^{\mathrm{TM}}$ Catalase activity Assay Colorimetric Kit (catalog number STA-341, Cell Biolabs, INC., Cambridge, UK) was used according to the manufacturer's instructions.

\subsection{Statistical Analysis}

Results were analyzed using GraphPad Prism software version 6.0. All data are presented as the mean $( \pm \mathrm{SD})$ for the number of determination shown in the figure. ANOVA was performed in Graphpad Prism version 6.0, followed by Dunnett's multiple comparisons test versus treated cells with $t$-BHP alone $*=p<0.05, * *=p<0.01, * * *=p<0.001$.

\section{Results}

\subsection{Effect of EYGF-23 on Caco-2 Cell Viability under Oxidative Stress}

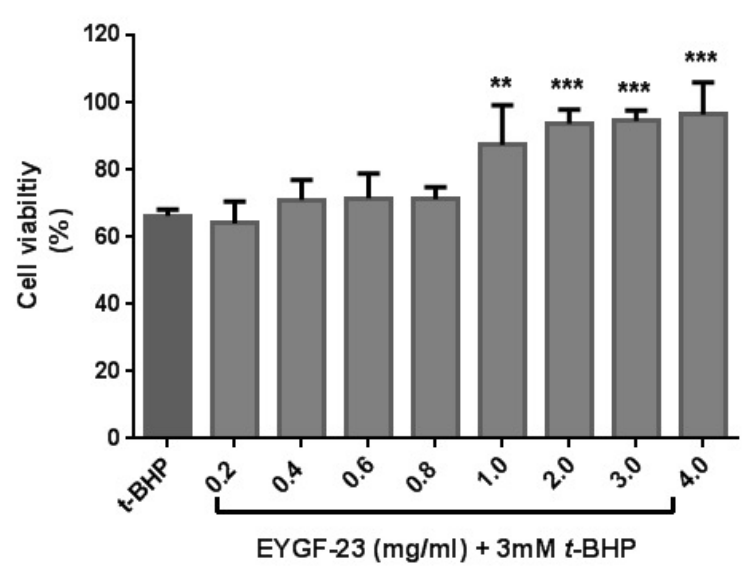

Figure 1. Effect of EYGF-23 on cell viability of Caco-2 cells stressed with $t$-BHP using MTT assay. The absorbance of solubilised formazan crystals was measured at $492 \mathrm{~nm}$. Data correspond to the means $\pm \mathrm{SD}$ of three independent experiments. ANOVA was performed in Graphpad Prism version 6.0. followed by Dunnett's multiple comparisons test. $* *=p<0.01$, $* * *=\mathrm{p}<0.001$ versus treated cells with $t$-BHP alone.

The effect of EYGF-23 alone on Caco-2 cell viability was measured to confirm that there is no cytotoxicity on cells (result not shown). As depicted in figure 1, cells treated with $0.2-0.8 \mathrm{mg} / \mathrm{ml}$ of EYGF-23 for 24 hour prior to be stressed with $t$-BHP demonstrated cell viability levels comparable to cells treated with $t$-BHP alone. At concentrations of EYGF- $23 \geq 1.0 \mathrm{mg} / \mathrm{ml}$, cell viability increased significantly compared with the $t$-BHP control $(p<0.01$ at least). Cell viability of $87.31 \%$ was achieved at $1.0 \mathrm{mg} / \mathrm{ml}(p<0.01)$, which continued to increase significantly when treated with 2.0, 3.0, and $4.0 \mathrm{mg} / \mathrm{ml}(93.70,94.45$, and $96.35 \%$ respectively; all $p<0.001)$. As concentrations of $1.0 \mathrm{mg} / \mathrm{ml}$
EYGF-23 and above significantly increased cell viability, the minimum dose of $1.0 \mathrm{mg} / \mathrm{ml}$ was used to conduct further experiments.

\subsection{Effect of EYGF-23 on Intracellular ROS levels and Lipid Peroxidation Products in Caco-2 Cells under Oxidative Stress}

The amount of ROS generated by untreated cells was significantly lower $(69.00 \% ; \quad p<0.001)$ than that produced by cells stressed with $t$-BHP (75.27\%), as shown in figure 2-A. ROS production levels in Caco-2 cells treated with 1.0 $\mathrm{mg} / \mathrm{ml}$ EYGF-23 under oxidative conditions were markedly inhibited to $60.00 \%(p<0.001)$ when compared with cells treated by $t$-BHP alone $(75.27 \%)$.

When Caco-2 cells were treated with $3 \mathrm{mM} t$-BHP for 2 hours, an almost 2-fold increase in lipid peroxidation products was observed compared with untreated cells (32.19 $\mu \mathrm{g} / \mathrm{ml}$ versus $19.85 \mu \mathrm{g} / \mathrm{ml}$, respectively) $(p<0.001)$ as measured by TBARS (figure 2-B). However, $1.0 \mathrm{mg} / \mathrm{ml}$ of EYGF-23 significantly inhibited the formation of MDA to a concentration of $24.15 \mu \mathrm{g} / \mathrm{ml}(p<0.05)$ in stressed cells when compared with cells treated by $t$-BHP alone (32.19 $\mu \mathrm{g} / \mathrm{ml})$.
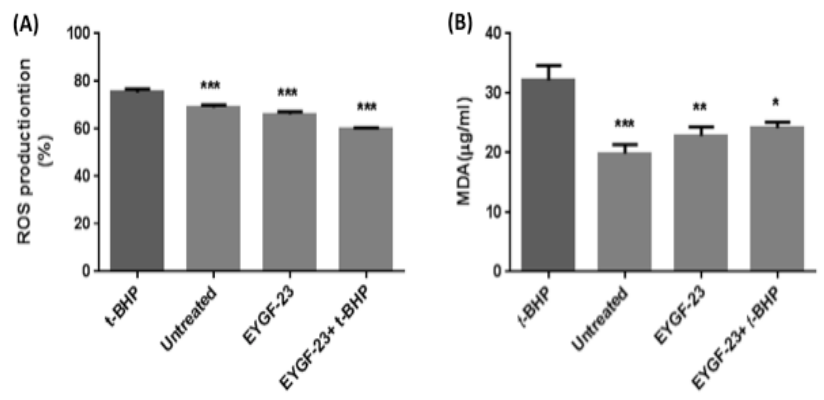

Figure 2. A) Measurement of intracellular ROS levels in Caco-2 cells using flow cytometry. Cellular ROS levels were monitored by loading treated cells with $\mathrm{CM}-\mathrm{H}_{2}$ DCFDA probe and measuring the intensity of DCF fluorescence at an excitation wavelength of 490 and an emission wavelength of $520 \mathrm{~nm} \mathrm{~B}$ ) Measurement of lipid peroxidation product (MDA) formed in Caco-2 cells using TBARS method. Data correspond to the means $\pm \mathrm{SD}$ of three independent experiments. ANOVA was performed in Graphpad Prism version 6.0. followed by Dunnett's multiple comparisons test. $*=\mathrm{p}<0.05, * *=\mathrm{p}<0.01, * * *=\mathrm{p}<0.001$ versus treated cells with $t$-BHP alone.

\section{3. Caspase Activity in Caco-2 Cells under Oxidative Stress}

Caspase 3/7 activity in Caco-2 cells under oxidative stress was assessed using a luminometer. As demonstrated in figure 3, Caco-2 cells exhibited high Caspase 3/7 activity when treated with the oxidant $t$-BHP alone $(78.0 \%)$. Caspase $3 / 7$ activity produced under oxidative stress was significantly inhibited to a third of this level (26.85\%), when cells were pre-treated with $1.0 \mathrm{mg} / \mathrm{ml} \mathrm{EYGF-23}(p<$ $0.001)$. These levels were comparable to when cells were treated with EYGF-23 alone, in the absence of stress induced by $t$-BHP. 


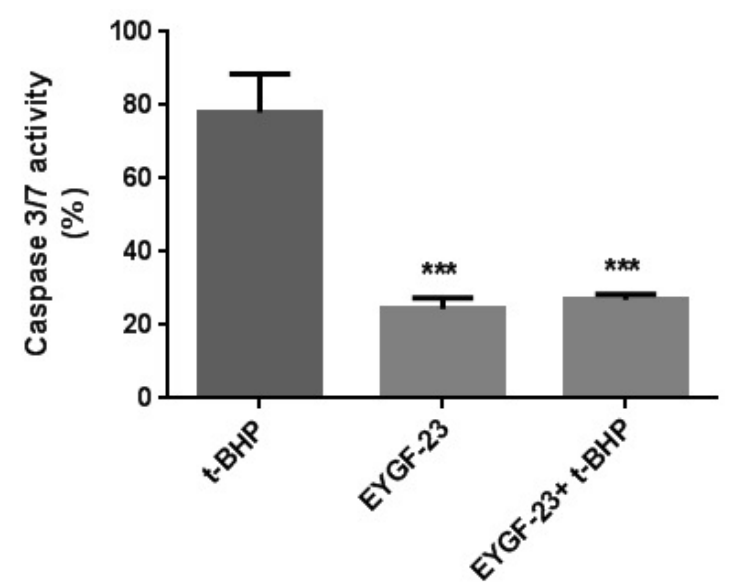

Figure 3. Measurement of caspase $3 / 7$ activity in Caco-2 cells using a luminometer. Data correspond to the means $\pm \mathrm{SD}$ of three independent experiments. ANOVA was performed in Graphpad Prism version 6.0. followed by Dunnett's multiple comparisons test. $*=p<0.05$, $* *=p<0.01$, $* * *=\mathrm{p}<0.001$ versus treated cells with $t$-BHP alone.

(A)

(B)
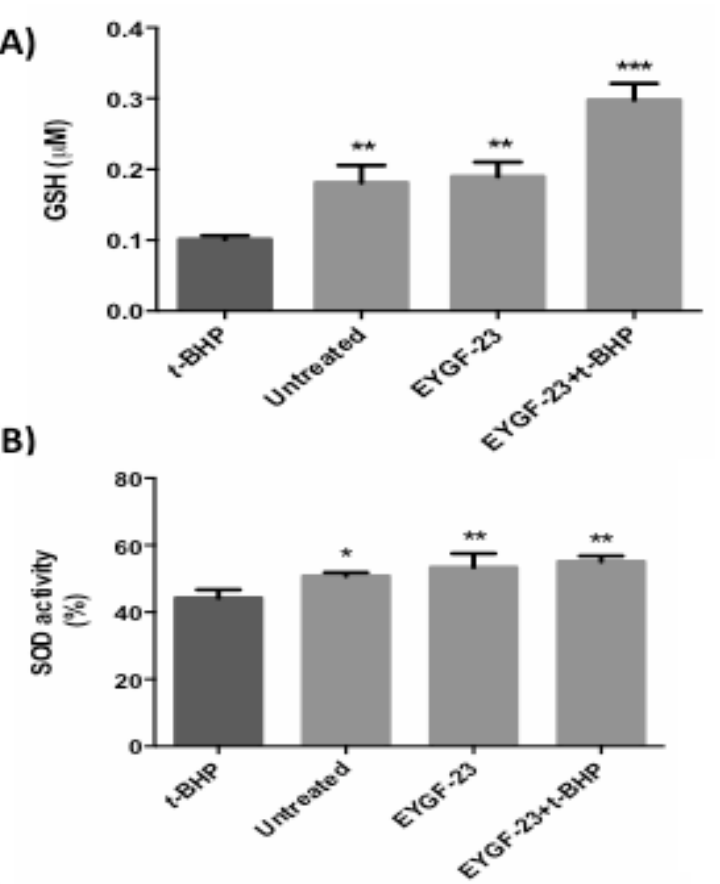

(C)

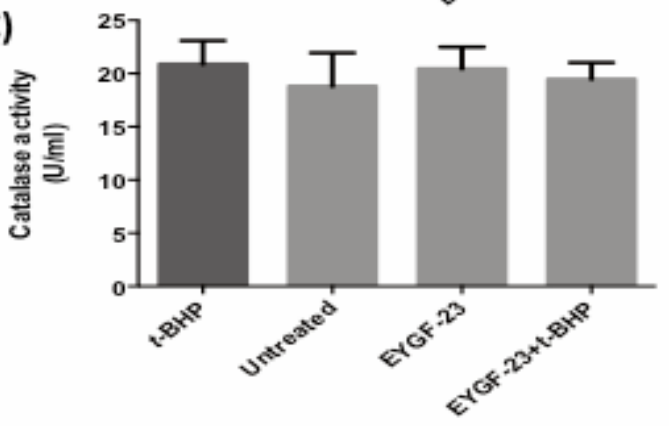

Figure 4. Effect of EYGF-23 on A) the amount of total glutathione (GSH) $\mathrm{B})$ the percentage of superoxide dismutase (SOD) activity and C) the level of catalase in Caco-2 cells. Data correspond to the means \pm SD of three independent experiments. ANOVA was performed in Graphpad Prism version 6.0. followed by Dunnett's multiple comparisons test. ${ }^{*}=p<0.05$, $* *=p<0.01, * * *=p<0.001$ versus treated cells with $t$-BHP alone.

\subsection{Influence of EYGF-23 on Antioxidant Defence Systems}

There was a significant depletion of total glutathione in cells treated with $t$-BHP (glutathione $0.10 \mu \mathrm{M}$ ) compared with untreated cells $(0.18 \mu \mathrm{M} ; p<0.01)$. Total glutathione level was significantly elevated in stressed cells pretreated with $1.0 \mathrm{mg} / \mathrm{ml}$ EYGF-23 $(0.29 \mu \mathrm{M})$ in comparison to cells treated with $t$-BHP alone $(p<0.001)$. These findings are represented in figure 4-A. Figure 4-B illustrates that SOD activity was significantly inhibited in cells stressed with $t$-BHP (44.22\%) compared with untreated cells $(50.75 \%$; $p$ $<0.05$ ). Cells treated with $1.0 \mathrm{mg} / \mathrm{ml}$ EYGF-23 prior to oxidative induction exhibited significantly higher SOD activity $(55.10 \%)$ when compared with cells treated with $t$-BHP $(p<0.01)$. There was no significant difference in the concentration of catalase between untreated cells $(18.80$ $\mathrm{U} / \mathrm{ml})$, cells treated with $t$-BHP alone $(20.88 \mathrm{U} / \mathrm{ml})$ and cells pretreated with $1.0 \mathrm{mg} / \mathrm{ml} \mathrm{EYGF-23} \mathrm{prior} \mathrm{to} \mathrm{their} \mathrm{exposure}$ to $t$-BHP $(19.46 \mathrm{U} / \mathrm{ml})$ (figure 4-C).

\section{Discussion}

The results obtained in figure 1 indicated that the EYGF-23 egg yolk peptide had the ability to enhance cell viability and to protect $\mathrm{Caco}-2$ cells from the oxidative toxicity induced by $t$-BHP. Cell protection that achieved when cells pretreated with EYGF-23 fraction back to the ability of this fraction to scavenge toxic radicals [10]. The inhibition of cellular ROS concentration (figure 2-A) and MDA level (figure 2-B) in Caco-2 cells pretreated with EYGF-23 under oxidative conditions confirmed the scavenging activity of this fraction. These results concur with those observed with peptides isolated from hoki fish on human embryonic lung fibroblasts [12] and silver carp fish peptides in human intestinal epithelial Caco-2 cells [13]. The results for the protective effect of EYGF-23 in cells complement non-cellular antioxidant activity (peroxide value, TBARS, DPPH and hydroxyl radical scavenging) that we reported previously for this fraction [10]. The EYGF-23 fraction showed a predominance of hydrophobic amino acids tyrosine and tryptophan as shown by amino acid analysis. Furthermore, in the previous paper [10] we also identified peptides WYGPD, TMFPSA and WIHNENQGF containing hydrophobic amino acids tyrosine (Y) and tryptophan (W) in the EYGF-23 fraction that showed excellent DPPH radical scavenging activity. Therefore, it is highly likely that these identified peptides also contributed to the antioxidant activity of the fraction in the present cellular study, thus confirming the structure-function relationship of egg yolk peptides in their antioxidant and protective role. Cells of the intestinal epithelium have a very rapid cell turnover rate because tissue homeostasis is balanced by cell proliferation and cell death. Any inducing shifts in the redox balance by oxidants such as $t$-BHP could lead to an enhancement in mutagenic and apoptotic 
responses. Subtoxic levels of hydroperoxide result in DNA damage and apoptosis, via the activation of the caspase family [14]. Caspases 3 and 7 are members of this family and represent the downstream caspases. They are activated by the upstream proteases and act by themselves to cleave cellular targets [15]. In the current study, the caspase 3/7 activity was markedly high (78.0\%) in cells stressed with $t$-BHP without pre-treatment with EYGF-23. EYGF-23 peptides, through their role as antioxidants, may intercept the free-radical chain reaction, preventing caspase activation thereby inhibiting cell apoptosis (figure 3). In a healthy system, a high level of total glutathione plays a substantial role in protecting cells from unexpected attack by hydroxyl radicals. Under oxidative stress, the increase in concentration of peroxides leads to a shift in thiol redox status represented by a severe decrease in the reduced form of glutathione (GSH) and an increase in the level of the oxidised form (GSSG). In the current study, $3 \mathrm{mM}$ of $t$-BHP caused significant depletion of total glutathione, but importantly this was elevated to be higher than the basal level when cells were treated with the isolated fraction prior to stress induction (figure 4-A). The findings related to the imbalance of reduced and oxidised forms of glutathione due to $t$-BHP, led to further examination of other antioxidant enzymes namely SOD and catalase in Caco- 2 cells, when treated with EYGF-23 under oxidative stress. SOD is responsible for the dismutation of the superoxide anion to hydrogen peroxide and a molecule of oxygen [16]. In this study (figure 4-B), cells treated with $1.0 \mathrm{mg} / \mathrm{ml} \mathrm{EYGF-23}$ prior to oxidative induction, exhibited significantly higher SOD activity $(55.10 \%)$ as compared with cells treated with $t$-BHP alone $(p<0.01)$. These findings illustrate the effect of EYGF-23 on enhancing the activity of SOD under oxidative stress. In contrast, there was no significant difference in catalase levels between cells stressed with $t$-BHP and unstressed cells (figure 4-C); this may be explained as follows. The role of catalase enzyme in the defence system is to catalyse the decomposition of $\mathrm{H}_{2} \mathrm{O}_{2}$ to water and oxygen; this action is similar to the role of glutathione peroxidase. Baud et al. [17] measured the $\mathrm{K}_{\mathrm{m}}$ value (which represents the affinity between the enzyme and the substrate) of catalase and glutathione peroxidase. These authors found that the high $\mathrm{K}_{\mathrm{m}}$ of catalase in removing $\mathrm{H}_{2} \mathrm{O}_{2}$ (up to $25 \mathrm{mM}$ ) was 4000 -fold higher than the $\mathrm{K}_{\mathrm{m}}$ of glutathione peroxidase $(6 \mu \mathrm{M})$; this indicated a lower level of activity for catalase as compared to that of glutathione peroxidase. The concentration level of $t$-BHP used in this study may, therefore, not be enough to activate catalase and may explain why there was no significant difference in the amount of catalase between cells stressed with $t$-BHP and unstressed cells (figure 4-C). Although the molecular mechanism of EYGF-23 in the induction of antioxidative enzymes is not fully understood, similar up-regulation of antioxidative enzymes has been observed following the administration of antioxidants. For example, gelatin hydrolysate, obtained from hoki skin, significantly increased levels of superoxide dismutase, catalase and glutathione peroxidase in a hepatoma cell line [18]. Young et al. [19] also prepared egg yolk peptides that have the ability to increase the glutathione levels in red blood cells by increasing its synthesis.

\section{Conclusions}

Purified egg yolk peptides (Fraction EYGF-23) possessed antioxidant activity in oxidatively stressed Caco-2 cells and protected them against programmed cell death. The protective effect of EYGF-23 was demonstrated by the significant increase in Caco-2 cell viability under stressed conditions (3 mM $t$-BHP). Intracellular ROS and malondialdehyde levels were also reduced in stress-induced cells treated with EYGF-23. Moreover, EYGF-23 was able to inhibit the activity of caspase 3/7 in stressed cells and thus protected cells from induced caspase-dependent apoptosis. EYGF-23 was able to increase the level of total glutathione and SOD activity but had no significant effect on the level of catalase, thus elucidating its method of action. All of these findings indicate that the isolated egg yolk fraction (EYGF-23) acted as an antioxidant and caused favorable changes within the caco-2 cells, thereby protecting them from oxidative stress conditions. The relation between previously identified amino acids composition, peptide sequences and anti-oxidative activity of EYGF-23 was highlighted in this study. These novel findings may have potential applications in the nutraceuticals market.

\section{Conflict of Interest}

There is no conflict of interest.

\section{REFERENCES}

[1] Ray, P. D., Huang, B. W., \& Tsuji, Y. Reactive oxygen species (ROS) homeostasis and redox regulation in cellular signaling. Cellular signalling, 24 (5), 981-990, 2012.

[2] Halliwell, Barry, and John MC Gutteridge. Free radicals in biology and medicine. Oxford University Press, USA, 2015.

[3] Valko, M., Izakovic, M., Mazur, M., Rhodes, C. J. \& Telser, J. Role of oxygen radicals in DNA damage and cancer incidence. Mol Cell Biochem, 266, 37-56, 2004.

[4] Cimen, M. Free radical metabolism in human erythrocytes. Biochemical Pharmacology, 390, 1-11, 2008.

[5] Matés, José M., et al. Oxidative stress in apoptosis and cancer: an update. Archives of toxicology 86 (11)1649-1665, 2012.

[6] Meunier, V., Bourrie, M., Berger, Y. \& Fabre, G. The human intestinal epithelial cell line Caco-2; pharmacological and pharmacokinetic applications. Cell Biology and Toxicology, 11, 187-194, 1995. 
[7] Kim, Y., Choi, Y., Ham, H., Jeong, H.S. \& Lee, J. Protective effects of oligomeric and polymeric procyanidin fractions from defatted grape seeds on tert-butyl hydroperoxide-induced oxidative damage in HepG2 cells. Food Chemistry 2012.

[8] Lapshina, E. A., Zavodnik, I. B., Labieniec, M., Rękawiecka, K. \& Bryszewska, M. Cytotoxic and genotoxic effects of tert-butyl hydroperoxide on Chinese hamster B14 cells. Mutation Research/Genetic Toxicology and Environmental Mutagenesis, 583, 189-197, 2005.

[9] Katayama, S., Xu, X., Fan, M. Z. \& Mine, Y. Antioxidative stress activity of oligophosphopeptides derived from hen egg yolk phosvitin in Caco-2 cells. Journal of Agricultural and Food Chemistry, 54, 773-778, 2006.

[10] Yousr, M. \& Howell, N. Antioxidant and ACE inhibitory bioactive peptides purified from egg yolk proteins. International Journal of Molecular Sciences, 16(12), 29161-29178, 2015.

[11] Omar, U., Aloqbi, A., Yousr, M. \& Howell, N. Protective Effects of Punicalagin on Caco-2 Intestine Cell Line under Oxidative Stress Caused by Tert-butyl hydroperoxide. Journal of Pharmacy and Nutrition Sciences, 249-256, 2015.

[12] Kim, S.Y., Je, J.Y. \& Kim, S.K. Purification and characterization of antioxidant peptide from hoki (Johnius belengerii) frame protein by gastrointestinal digestion. The Journal of Nutritional Biochemistry, 18, 31-38, 2007.

[13] Zhong, S., Ma, C., Lin, Y. C. \& Luo, Y. Antioxidant properties of peptide fractions from silver carp
(Hypophthalmichthys molitrix) processing by-product protein hydrolysates evaluated by electron spin resonance spectrometry. Food Chemistry, 126, 1636-1642, 2011.

[14] Dandrea, T., Hellmold, H., Jonsson, C., Zhivotovsky, B., Hofer, T., Wärngård, L. \& Cotgreave, I. The transcriptosomal response of human A549 lung cells to a hydrogen peroxide-generating system: relationship to DNA damage, cell cycle arrest, and caspase activation. Free Radical Biology and Medicine, 36, 881-896, 2004.

[15] Danial, N. N. \& Korsmeyer, S. J. Cell death: critical control points. Cell, 116, 205-219, 2004.

[16] Inoue, M., Sato, E. F., Nishikawa, M., Park, A.-M., Kira, Y., Imada, I. \& Utsumi, K. Mitochondrial generation of reactive oxygen species and its role in aerobic life. Current Medicinal Chemistry, 10, 2495-2505, 2003.

[17] Baud, O., Greene, A. E., Li, J., Wang, H., Volpe, J. J. \& Rosenberg, P. A. Glutathione peroxidase-catalase cooperativity is required for resistance to hydrogen peroxide by mature rat oligodendrocytes. The Journal of Neuroscience, 24, 1531-1540, 2004.

[18] Mendis, E., Rajapakse, N. \& Kim, S. K. Antioxidant properties of a radical-scavenging peptide purified from enzymatically prepared fish skin gelatin hydrolysate. Journal of Agricultural and Food Chemistry, 53, 581-7, 2005.

[19] Young, D., Fan, M. Z. \& Mine, Y. Egg yolk peptides up-regulate glutathione synthesis and antioxidant enzyme activities in a porcine model of intestinal oxidative stress. Journal of Agricultural and Food Chemistry, 58, 7624-7633, 2010 